University of Nebraska - Lincoln

DigitalCommons@University of Nebraska - Lincoln

\title{
Sexually dimorphic aggression indicates male gray wolves specialize in pack defense against conspecific groups
}

\author{
Kira A. Cassidy \\ Yellowstone Wolf Project, kira_cassidy@nps.gov \\ L. David Mech \\ USGS Northern Prairie Wildlife Research Center, david_mech@usgs.gov \\ Daniel R. MacNulty \\ Utah State University, dan.macnulty@usu.edu \\ Daniel R. Stahler \\ Yellowstone Wolf Project \\ Douglas W. Smith \\ Yellowstone Wolf Project
}

Follow this and additional works at: https://digitalcommons.unl.edu/usgsnpwrc

Part of the Animal Studies Commons

Cassidy, Kira A.; Mech, L. David; MacNulty, Daniel R.; Stahler, Daniel R.; and Smith, Douglas W., "Sexually dimorphic aggression indicates male gray wolves specialize in pack defense against conspecific groups" (2017). USGS Northern Prairie Wildlife Research Center. 311.

https://digitalcommons.unl.edu/usgsnpwrc/311

This Article is brought to you for free and open access by the US Geological Survey at DigitalCommons@University of Nebraska - Lincoln. It has been accepted for inclusion in USGS Northern Prairie Wildlife Research Center by an authorized administrator of DigitalCommons@University of Nebraska - Lincoln. 
Research paper

\title{
Sexually dimorphic aggression indicates male gray wolves specialize in pack defense against conspecific groups
}

\author{
Kira A. Cassidy a,b,*, L. David Mech ${ }^{\mathrm{c}}$, Daniel R. MacNulty ${ }^{\mathrm{d}}$, Daniel R. Stahler ${ }^{\mathrm{b}}$, \\ Douglas W. Smith ${ }^{\mathrm{b}}$ \\ a Natural Resource Science and Management, 115 Green Hall, 1530 Cleveland Avenue N, University of Minnesota, St. Paul, MN, 55108, USA \\ b Yellowstone Wolf Project, PO Box 168, Yellowstone Center for Resources, Yellowstone National Park, WY, 82190, USA \\ c U. S. Geological Survey, Northern Prairie Wildlife Research Center, 8711-37th St., S.E., Jamestown, ND, 58401-7317, USA \\ d Department of Wildland Resources, Utah State University, Logan, UT, 84322, USA
}

\section{A R T I C L E I N F O}

\section{Article history:}

Received 18 May 2016

Received in revised form

25 November 2016

Accepted 18 January 2017

Available online 29 January 2017

\section{Keywords:}

Aggression

Canis lupus

Conflict

Fighting

Individual variation

Intraspecific strife

Mortality

Sexual dimorphism

Territoriality

\begin{abstract}
A B S T R A C T
Aggression directed at conspecific groups is common among gregarious, territorial species, and for some species such as gray wolves (Canis lupus) intraspecific strife is the leading cause of natural mortality. Each individual in a group likely has different measures of the costs and benefits associated with a group task, such as an aggressive attack on another group, which can alter motivation and behavior. We observed 292 inter-pack aggressive interactions in Yellowstone National Park between 1 April 1995 and 1 April 2011 (>5300 days of observation) in order to determine the role of both sexes, and the influence of pack, age, and other traits on aggression. We recorded the behaviors and characteristics of all individuals present during the interactions ( $n=534$ individuals) and which individuals participated in each step (i.e. chase, attack, kill, flight) of the interaction. Overall, all wolves were more likely to chase rivals if they outnumbered their opponent, suggesting packs accurately assess their opponent's size during encounters and individuals adjust their behavior based on relative pack size. Males were more likely than females to chase rival packs and gray-colored wolves were more aggressive than black-colored wolves. Male wolves and gray-colored wolves also recorded higher cortisol levels than females and black-colored wolves, indicating hormonal support for more intense aggressive behavior. Further, we found a positive correlation between male age and probability of chasing, while age-specific participation for females remained constant. Chasing behavior was influenced by the sex of lone intruders, with males more likely to chase male intruders. This difference in behavior suggests male and female wolves may have different strategies and motivations during inter-pack aggressive interactions related to gray wolf mating systems. A division of labor between pack members concerning resource and territory defense suggests selection for specific traits related to aggression is an adaptive response to intense competition between groups of conspecifics.
\end{abstract}

(c) 2017 Elsevier B.V. All rights reserved.

\section{Introduction}

Group territorial defense is common among social mammals (e.g. African lions [Panthera leo] Heinsohn, 1997; Mosser and Packer, 2009; chimpanzees [Pan troglodytes] Wilson and Wrangham, 2003; gray wolves [Canis lupus] Mech and Boitani, 2003; lemurs [Propithecus verreauxi] Koch et al., 2016; spotted hyenas [Crocuta crocuta] Henschel and Skinner, 1991; Boydston et al., 2001) with aggression defining many intergroup interactions. In some species, these encounters lead to a significant portion of natural mortality (Mech, 1977; Mech, 1994; Creel and Creel, 1998;

* Corresponding author at: Natural Resource Science and Management, 115 Green Hall, 1530 Cleveland Avenue N, University of Minnesota, St. Paul, MN, 55108, USA. E-mail address: kira_cassidy@nps.gov (K.A. Cassidy).
Murray et al., 2010; Cubaynes et al., 2014). Although group-contest studies are often examined with respect to numerical assessment (McComb et al., 1994; Bonanni et al., 2011; Furrer et al., 2011), recently, a few studies have examined group composition and the differing roles of certain individuals during intergroup interactions (e.g. chimpanzees Wilson et al., 2001, Wilson et al., 2012; Japanese macaques [Macaca fuscata yakui] Majolo et al., 2005; olive baboons [Papio anubis] MacCormick et al., 2012; gray wolves Cassidy et al., 2015).

Differences in aggressive behavior between males and females have been demonstrated in many species (e.g. feral domestic dogs [Canis familiaris] Pal et al., 1998; brown hyenas [Hyaena brunnea] Mills, 1983; African lions McComb et al., 1994; slender-tailed meerkats [Suricata suricatta] Doolan and Macdonald, 1996, spotted hyenas Boydston et al., 2001; and chimpanzees Wilson et al., 2001). Presumably, individuals in a group will invest in aggressive terri- 
torial behavior based on their potential individual costs or benefits from the defense of the group's territory (Milinski and Parker, 1991; Pusey and Packer, 1997; Boydston et al., 2001). Sexually dimorphic behavior during aggressive interactions with rival groups suggests the sexes experience different costs and benefits such as changes in breeding opportunity (Darwin, 1871; Clutton-Brock, 2016); particularly since aggression is often directed at same-sex intruders (Rood, 1983; Grinnell et al., 1995; Heinsohn and Packer, 1995; Boydston et al., 2001). Mech (1999) first used the term "division of labor" regarding the behavior of wild gray wolves in relation to pup rearing which was split into defense (females dominate) and food-provisioning (males dominate). Male wolves are larger than females (Butler et al., 2006; Mech, 2006), are better at grappling large prey (MacNulty et al., 2009a), and may have specialized physiological adaptations for aggressive conflicts and a more-significant role during intergroup interactions (Morris and Brandt, 2014). A dichotomy between the specific roles of males and females in a pack likely result from physiological, behavioral, and hormonal differences.

Differences in behavior may suggest gray wolf packs experience a collective action problem (Olsen 1965), as has been described in other species (Heinsohn and Packer, 1995; Bonanni et al., 2010; Willems et al., 2013) where defecting or free-riding are strategies used by some individuals to gain the benefits of group cooperative action without the costs or risks (MacNulty et al., 2012; Willems and van Schaik, 2015). However, for a group-living, territorial species like the gray wolf, cooperating to maintain group size may be a driving force in participation during aggressive inter-group encounters, as most natural mortality is caused by intraspecific conflict between groups (Cubaynes et al.2014). Therefore, gray wolves may instead operate in alignment with the group augmentation theory which suggests that group members will exhibit helping behavior if the result of their helping increases their survival or reproduction in the future (Kingma et al., 2014). Examining aggressive interaction participation rates between sexes, age classes, phenotypic traits, and breeding status will help deduce which strategy has led to the evolution of the gray wolf social system.

We evaluated trait-specific differences in aggressive behavior during inter-pack interactions using 16 years of individual-based behavioral observations following the gray wolf reintroduction to Yellowstone National Park, Wyoming (Bangs and Fritts, 1996; Smith and Bangs, 2009). During the data-collection period we witnessed and documented 292 intergroup interactions involving 534 individuals. In nearly every case we were able to determine the interaction's outcome and the role of identifiable individual pack members and catalog their level of participation.

We predicted that males would consistently show higher participation than females during the aggressive parts of the interaction, similar to some primates (e.g. chimpanzees Wilson et al., 2014; olive baboons MacCormick et al., 2012), carnivores (e.g. African lions Mosser and Packer, 2009), and other social species (e.g. feral horses [Eqqus ferus] Miller, 1981). In some species, juveniles participate minimally, and aggression increases with age (Feldman, 1990; Pal et al., 1998). Among wolves, age has strong effects on hunting behavior and reproduction with older individuals having a lower probability of hunting success (MacNulty et al., 2009b) and older females producing fewer pups per litter (Stahler et al., 2013), suggesting that prime-aged wolves may be the most fit and therefore the most aggressive. However, in an examination of intergroup interactions in gray wolves living in Yellowstone (using the same interaction data as this analysis), the presence of old adults (>6 years) was a significant factor in successful contest wins (Cassidy et al., 2015).While prime-aged individuals are at their physical peak, the oldest individuals may exhibit increased aggression towards opponents in protection of future, dwindling breeding opportunity (i.e. the Terminal Investment Hypothesis (Williams,
1966)) and current offspring investment. We therefore predicted that aggression would increase with age, but possibly not at the same rate for both sexes. We also tested for an effect of breeding status on aggression, as has been found related to social status and aggression in other social species such as chimpanzees (Muller and Wrangham, 2004) and horses (York and Schulte, 2014). Breeders may be more likely to chase other wolves they view as competitors for future breeding opportunities.

We included coat color in our analysis to test for differences in aggressive behavior between black and gray phenotypes. Black coat color in wolves and dogs is due to a mutation in a $\beta$-defensin gene (CDB103 or K-locus) whose $K^{B}$ allele is dominant to the wildtype allele for agouti and binds with the melanocortin 1 receptor (Candille et al., 2007; Anderson et al., 2009). The capacity for $K^{B}$ to competitively bind with other melanocortin receptors (Candille et al., 2007) that modulate aggressive behavior (Ducrest et al., 2008) may decrease aggression in black wolves. For example, competitive displacement of adrenocorticotropic hormone (ACTH) from the melanocortin 2 receptor would inhibit glucocorticoid synthesis (Almasi et al., 2010), and lower glucocorticoid levels have been linked to diminished aggression in dogs (Rosado et al., 2010) and other vertebrates (Kruk et al., 2004; Summers and Winberg, 2006). In support of this mechanism, there is evidence that black dogs have lower basal cortisol levels (Bennett and Hayssen, 2010) and aggression rates (Houpt and Willis, 2001; Amat et al., 2009) than nonblack dogs. Previous studies on this population indicate glucocorticoid levels changed with dominance status but not with intra-pack aggression (Creel, 2005).

Based on individual aggression studies in other species we predicted that (1) male wolves would be more aggressive than females during inter-pack interactions, (2) males would be more aggressive during interactions with intruding males, (3) females would be more aggressive during interactions with intruding females, (4) aggression in both sexes would increase with age but perhaps at different rates, (5) breeders would be more aggressive than nonbreeders, and (6) gray wolves would be more aggressive, and have higher cortisol levels, than black wolves. We discuss the implications of our results with respect to the adaptive advantages and complications of physical, hormonal, and behavioral differences among individuals during intergroup conflicts.

\subsection{Study system}

We collected all data in the Northern Range $\left(1000 \mathrm{~km}^{2}\right)$ of Yellowstone National Park $\left(8991 \mathrm{~km}^{2}\right)$. The Northern Range is defined by the winter distribution of the northern Yellowstone elk (Cervus elaphus) population. Elevations there vary from 1500 to $2400 \mathrm{~m}$, with high elevations characterized by conifer forests and low elevations by open grass meadows and shrub-steppe vegetation (Houston, 1982). The area experiences long, cold winters and short, cool summers (Dirks and Martner, 1982) and features a high wolf density fluctuating between 20.1 and 98.5 wolves $/ 1000 \mathrm{~km}^{2}$ with an average of 55.8 (Smith et al., 2011).

Wolves in the Northern Range primarily hunt elk (Smith et al., 2004; Metz et al., 2011) and all areas within Yellowstone National Park are protected from human activities such as development, hunting, and livestock grazing.

\section{Methods}

\subsection{Telemetry collars}

As part of its long-term research, the Yellowstone Wolf Project captures 15-30 wolves each year during the winter months via aerial darting. Biologists fit wolves with standard Very High Fre- 
quency radio collars (Telonics, Inc. Mesa, AZ) or Global Positioning System radio collars (Smith and Bangs, 2009). The National Park Service approved all capture and handling protocols and confirmed they were in accordance with recommendations from the American Society of Mammalogists (Sikes and Gannon, 2011).

\subsection{Data collection}

Observers recorded wolf behavior during daily tracking of radiocollared individuals from the ground. When a signal was detected, they searched for the pack or individual using spotting scopes with 20-60 $\times$ zoom, and observed the packs most often from distances of 0.25 to 6.00 kilometers. Observers recorded inter-pack interactions ad libitum (Altmann, 1974) and observed the interactions only in the Northern Range where they could make year-round observations.

\subsubsection{Individual characteristics}

We recorded individuals' sex, color (black or gray), weight, and estimated age during the capture and radio-collaring process, and determined their breeding status during subsequent field observations. We used year-round observations to determine sex, age, color, and breeding status of uncollared individuals. After repeated observations, many uncollared wolves were individuallyrecognizable based on body morphology, pelage coloration, and injuries (e.g. permanent limp, mange).

We used urination posture to determine sex of unmarked individuals. Males performed standing urinations or raised-leg urinations whereas females performed squat urinations or flexed-leg urinations (Peters and Mech, 1975).

We used tooth wear to determine age on captured, live individuals (Gipson et al., 2000) and used cementum annuli measurements on dead individuals (Ballard et al., 1995; Landon et al., 1998) to determine birth year. We considered wolves captured as adults to be known-aged only if they were individually recognized as pups due to morphological features. We used continuous ages for this study (range: 55 days to 10.55 years) and excluded data for wolves less than six-months old. Wolves younger than six months were generally stationed at a den or rendezvous site. At approximately six months wolf pups began to travel with the pack adults and participating in inter-pack interactions (Mech and Boitani, 2003).

We observed breeding behavior and distinguished an individual as a breeder if we observed it in a copulatory tie or actively trying to copulate during the current year's breeding season (Stahler et al., 2013). We also used genetic analysis to determine breeding status, assigning a wolf as a breeder if results confirmed at least one offspring was sampled (vonHoldt et al., 2008; Stahler et al., 2013).

During capture operations we also drew approximately $7 \mathrm{ml}$ of whole blood from the cephalic vein in order to test cortisol levels. Cortisol was measured with a competitive chemiluminescent immunoassay using reagents specifically designed for the automated IMMULITE ${ }^{\circledR}$ /IMMULITE ${ }^{\circledR} 1000$ systems, manufactured by Siemens Healthcare Diagnostics, Los Angeles, CA. This assay has been validated by the Animal Health Diagnostic Center (AHDC) Endocrinology Laboratory, College of Veterinary Medicine, Cornell University for diagnostic quantification of cortisol in unextracted canine (reference level 1.8-4.0 ug/dL) and feline serological samples (Reimers et al., 1996; Singh et al., 1997). The calibration range was $1-50 \mathrm{ug} / \mathrm{dL}$ and the analytical sensitivity was $0.2 \mathrm{ug} / \mathrm{dL}$. Capture operations can affect many stress-related hormones in wild wolves so cortisol levels cannot be considered typical. However, because all wolves are captured using the same process, the stress experienced is reasonably uniform and we believe the comparisons between the sexes and the colors are valid.

\subsubsection{Intergroup interactions}

We determined an interaction occurred when at least one wolf had auditory (howling) or visual contact (looking in the direction of opponent and reacting either by subsequently running away or charging forward) with a lone wolf or at least one wolf from a different pack. We then defined interactions as either aggressive or nonaggressive. Nonaggressive interactions consisted of howling and/or socializing (friendly interactions where a wolf/wolves from different packs were $<2 \mathrm{~m}$ apart and no chasing occurred; often characterized by tail-wagging and sniffing). Aggressive interactions included a chase at some point during the interaction. A chase occurred if at least one wolf ran toward at least one opposing wolf, and that wolf fled. Occasionally wolves or packs ran toward each other and chased back and forth before one pack or individual fled. In such cases a chase was always accompanied by a wolf eventually fleeing. Interactions escalated to an attack if at least two opponents made contact (usually biting) and to a kill if an individual was attacked and killed or fatally wounded. For each interaction we determined a winner and a loser based on which pack displaced the other.

We further classified aggressive interactions based on both groups' compositions. When two packs of two or more individuals interacted we considered it a pack-pack (PP) interaction, when a pack interacted with a single, non-pack member, a pack-individual (PI) interaction, and when two single individuals from different packs interacted, an individual-individual (II) interaction.

\subsubsection{Individual behavior}

We determined a wolf was present if it was observed between the start and end times of the interaction. We then scored individual participation (i.e. participated Yes/No) in each of the steps of an interaction: chase, attack, kill, and/or flight. We considered a wolf to be more aggressive than another if it participated in a more intense level of aggressive behavior, defined as follows: kill $>$ attack $>$ chase $>$ present-only $>$ flee. Some wolves were present during an aggressive interaction yet did not participate in any of the behaviors.

For each intergroup interaction, we recorded: (1) the individuals present and their age, sex, color, and breeding status (see below for details on individual characteristic data collection), (2) time observation began, (3) time it ended, (4) which group initiated interaction, (5) the locations using 1983 Universal Transverse Mercator (UTM83) coordinates from maps of both groups at the beginning and the end of the interaction, (6) the behavior of all individuals in each group related to participation in the chase, attack, kill, or flight, and (7) the results of the interaction: win or loss.

\section{Data analysis}

To understand differences in individual chasing behavior during inter-pack interactions we used generalized linear mixed models (GLMMs) with a binomial distribution. We tested for effects from the individual's relative packs size (RPS), sex, age, color, breeding status, and weight. We also considered the type of interaction (PP or PI) as a possible influence on aggression and, in some cases, analyzed them separately. To account for unmeasured, idiosyncratic variables associated with certain individuals and repeated measures of individuals, we included wolf identity (WOLF_ID) as a random intercept.

We used piece-wise linear splines to test for nonlinear effects of age on an individual's probability of chasing and created a variable containing a linear spline for age with the MKSPLINE command in Stata 12.0. We constructed the variables so that the estimated coefficients measure the slopes before and after a breakpoint. Specifically, we tested our prediction that chasing would increase 
linearly with age, rather than level-off or even decrease at advanced ages. We set breakpoints at age increments of six months. This ensures the individual behavior was captured seasonally (winter versus pup-rearing season) and could therefore be used to test for changes in behavior from one season, and then one year, to the next.

To find the most parsimonious model for factors affecting participation in a chase, we first determined the best functional form of age-specific effects on chasing. Although we collected data on attacking and killing, chasing was the only dependent variable with enough data to analyze given the need to control for repeated individuals involved in the aggressive interactions. We selected knots (breakpoints in the data to test for non-linearity) a priori in accordance with guidelines for the efficient use of knots (Eubanks, 1984; Seber and Wild, 2003). The best age model was the one with the lowest Akaike Information Criterion $\left(\mathrm{AIC}_{\mathrm{c}}\right)$, adjusted for small sample size (Burnham and Anderson, 1998). We added the best-fit age terms to several biologically feasible models. We included interactions between sex and age as we predicted changes with age to possibly be different between males and females and report means with standard errors.

To measure characteristics influencing aggression and to control for possible confounding factors, we tested several models: (1) null model, (2) relative pack size only, (3) RPS, sex, and age, and (4) RPS, sex, age, color, breeding status, and weight. RPS is equivalent to the difference between the group sizes of two opponents (e.g. RPS $=0$ for interactions between two opponents of equal size and can be negative [if focal pack is smaller than opponent] or positive [if focal pack is larger than opponent]). We further interpreted pack- and trait- effects by using the best model to construct fitted value plots for probabilities of chasing for each significant variable tested.

To test if male and female chasing was influenced by the identity of an intruder, we analyzed data from PI interactions where the sex of the intruder was known. This model test included RPS, age, sex, color, breeding status, and weight with wolf identity as a random intercept. We interpreted these effects by constructing fitted value estimates for males and females chasing intruders of both sexes.

The Cornell University Animal Health Diag nostic Center measured cortisol concentrations from 41 wolves at micrograms per deciliter $(\mu \mathrm{g} / \mathrm{dL})$ using $1 \mathrm{ml}$ of serum obtained from centrifuged whole blood collected from the cephalic vein during capture operations. We examined the cortisol results using a GLMM to determine the influences of male versus female and black versus gray wolves on cortisol levels.

\section{Results}

During $>5300$ observation days, we recorded 292 intergroup interactions for analysis: $121 \mathrm{PP}(41.4 \%), 166 \mathrm{PI}$ (56.9\%), and $5 \mathrm{II}$ interactions (1.7\%). During PI interactions, the pack always displaced the individual. A total of 543 distinct individuals were present for the interactions recorded. There were 246 males and 197 females with an age range from 55 days to 10.55 years. Average pack size was 8.07 (st dev $=4.62$ ).

Results from the piece-wise linear spline test indicated a breakpoint at age 1.5 for males only (Supplemental Information A \& B). This break demonstrates that the probability of participating in a chase increases rapidly from the time male wolves start to travel full-time with pack adults at six-months of age until they enter their second winter at 1.5 years old. From 1.5 years until 10 years of age, male probability of chasing then increases at a slower rate. The spline test indicated no breakpoint for females, although some breakpoints during prime-ages had $\triangle \mathrm{AIC}_{\mathrm{c}}$ scores of $<2$ and could plausibly be the best.

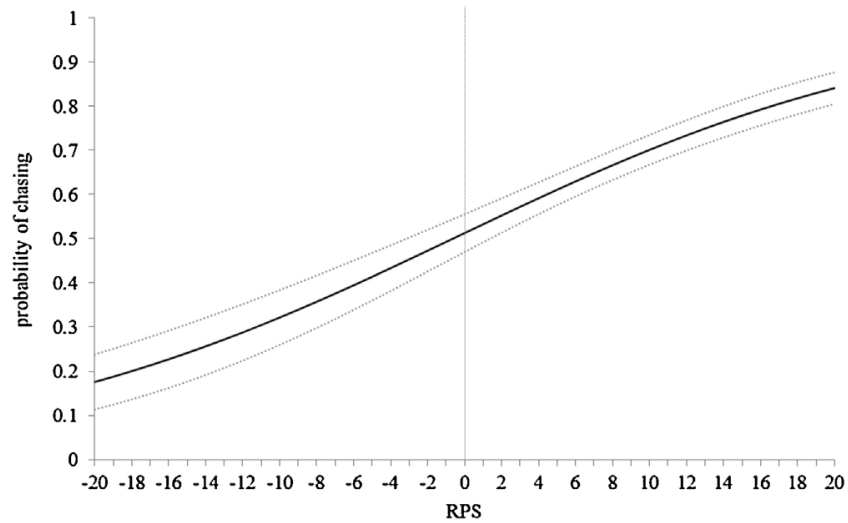

Fig. 1. Predicted probabilities (with $95 \%$ confidence intervals) of chasing for wolves when pack size is measured relative to the opponent (RPS $=0$ when the two packs are the same size) from the best-fit model (Table 2).

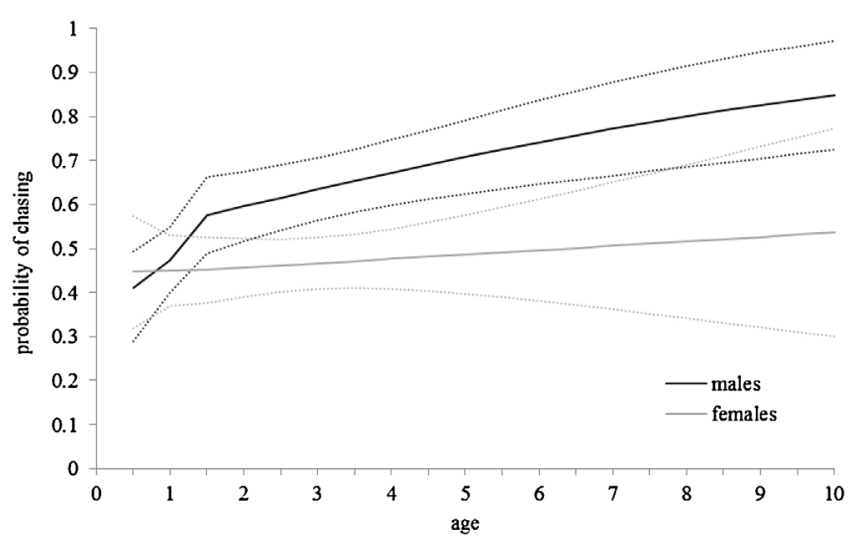

Fig. 2. Predicted probabilities (with $95 \%$ confidence intervals) of chasing for males (black line) and females (gray line) from six months to 10 years old from the best-fit model (Table 2).

Of the four models tested, the null model performed the poorest (Table 1 ). The best model (with a $\mathrm{W}_{\mathrm{i}}$ of 0.66 ) included RPS, sex, age spline $<1.5$ years, age spline $>1.5$ years, sex $\times$ age interaction $<1.5$, sex $\times$ age interaction $>1.5$, color, breeding status, and body weight (Table 2). The second best model (with a $\mathrm{W}_{\mathrm{i}}$ of 0.34 ) included all the same variables except for color, breeding status, and body weight. This model had a $\triangle \mathrm{AIC}_{\mathrm{c}}$ of 1.33 and could therefore be considered as plausible as the top-performing model. As expected, RPS $(\beta=0.083$, 95\% CIs: 0.067-0.100) was an important factor in individual aggression as a wolf was more likely to chase as RPS increased (when RPS $>0$ the individual wolf is part of a pack that outnumbers the opponent), and the probability of chasing increased throughout all RPS measures (Fig. 1). Each additional wolf relative to a rival increased the odds of chasing by $1.6 \%$.

Increasing RPS caused both male and female probabilities of chasing to increase with males always more likely to chase than females. Holding RPS fixed at 0 , male probability of chasing was 0.57 and female probability was 0.47 . Further, males were more likely than females to chase even when their pack was outnumbered. Male probability of chasing crossed the 0.50 threshold at an RPS of -3.5 , while females crossed 0.50 at 1.5 wolves, a difference of five pack members. A male's probability of chasing increased rapidly from 0.52 at age 0.5 to 0.70 at age 1.5 , then increased more slowly until reaching 0.90 at age 10 (Fig. 2). A female's probability of chasing was 0.59 at age 0.5 and 0.67 at age 10 remaining effectively constant with increasing age, although the 95\% confidence interval widens with female age (Fig. 2). In addition, males 
Table 1

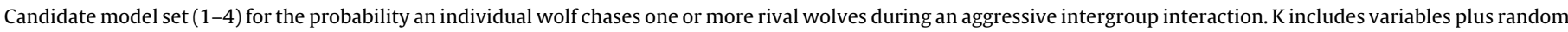
effect (WOLF_ID) and a constant.

\begin{tabular}{|c|c|c|c|c|c|c|c|}
\hline model no. & list of variables & no. of variables & $\mathrm{K}$ & LL & $\mathrm{AIC}_{\mathrm{c}}$ & $\Delta \mathrm{AIC}_{\mathrm{c}}$ & $\mathrm{W}_{\mathrm{i}}$ \\
\hline 1 & $\begin{array}{l}\text { a. } \text { RPS }^{*} \\
\text { b. sex } \\
\text { c. age spline }<1.5 \text { years } \\
\text { d. age spline }>1.5 \text { years } \\
\text { e. sex } \times \text { age interaction ( }<1.5 \text { years) } \\
\text { f. sex } \times \text { age interaction ( }>1.5 \text { years) } \\
\text { g. color } \\
\text { h. breeding status } \\
\text { i. weight }\end{array}$ & 9 & 11 & -955.808 & 1934.77 & 0.00 & 0.66 \\
\hline 2 & $\begin{array}{l}\text { a. } \text { RPS }^{*} \\
\text { b. sex } \\
\text { c. age spline }<1.5 \text { years } \\
\text { d. age spline }>1.5 \text { years } \\
\text { e. sex } \times \text { age interaction ( }<1.5 \text { years) } \\
\text { f. sex } \times \text { age interaction ( }>1.5 \text { years) }\end{array}$ & 6 & 8 & -959.742 & 1936.11 & 1.33 & 0.34 \\
\hline 3 & a. RPS* & 1 & 3 & -972.323 & 1950.75 & 15.97 & 0.00 \\
\hline 4 & NULL & 0 & 2 & -1027.024 & 2058.10 & 123.32 & 0.00 \\
\hline
\end{tabular}

*Relative Pack Size.

Table 2

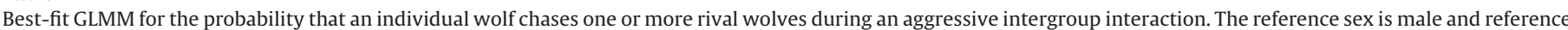
color is black. Individual wolf ID was included as a random effect.

\begin{tabular}{|c|c|c|c|c|c|c|}
\hline Parameter & $\beta$ & SE & $z$ & $P$ & $\begin{array}{l}95 \% \text { confidence } \\
\text { interval for } \beta\end{array}$ & \\
\hline RPS $^{*}$ & 0.083 & 0.008 & 9.92 & 0.000 & 0.067 & 0.100 \\
\hline sex & 0.711 & 0.481 & 1.48 & 0.140 & -0.233 & 1.654 \\
\hline $\begin{array}{l}\text { age spline } \\
<1.5 \text { years }\end{array}$ & 0.832 & 0.335 & 2.49 & 0.013 & 0.176 & 1.488 \\
\hline $\begin{array}{l}\text { age spline } \\
>1.5 \text { years }\end{array}$ & 0.168 & 0.066 & 2.55 & 0.011 & 0.039 & 0.297 \\
\hline $\begin{array}{l}\text { sex } \times \text { age } \\
\text { interaction } \\
(<1.5 \text { years })\end{array}$ & -0.811 & 0.393 & -2.06 & 0.039 & -1.582 & -0.040 \\
\hline $\begin{array}{l}\text { sex } \times \text { age } \\
\text { interaction } \\
(>1.5 \text { years })\end{array}$ & -0.128 & 0.087 & -1.47 & 0.142 & -0.298 & 0.043 \\
\hline color & 0.384 & 0.149 & 2.57 & 0.010 & 0.091 & 0.677 \\
\hline breeding status & -0.169 & 0.173 & -0.97 & 0.330 & -0.508 & 0.170 \\
\hline weight & -0.005 & 0.011 & -0.42 & 0.675 & -0.026 & 0.017 \\
\hline intercept & -1.233 & 0.564 & -2.19 & 0.029 & -2.338 & -0.128 \\
\hline
\end{tabular}

"Relative Pack Size.

Table 3

GLMM results from cortisol analysis of sex and color effects on cortisol levels $(n=41)$. The reference sex is female and the reference color is black.

\begin{tabular}{|c|c|c|c|c|c|c|}
\hline Parameter & $\beta$ & SE & $\mathrm{t}$ & $P>t$ & \multicolumn{2}{|c|}{ 95\% Confidence Interval for $\beta$} \\
\hline sex & 1.948 & 0.666 & 2.92 & 0.006 & 0.600 & 3.296 \\
\hline color & 1.559 & 0.668 & 2.34 & 0.025 & 0.208 & 2.911 \\
\hline intercept & 3.455 & 0.593 & 5.83 & 0.000 & 2.255 & 4.655 \\
\hline
\end{tabular}

showed higher levels of cortisol than females $(\beta=1.948,95 \%$ CIs: 0.600-3.296; Table 3, Fig. 3).

Coat color was also included in the best-fit model as a predictor of aggression. Specifically, a gray wolf was more likely than a black wolf to chase ( $\beta=0.384,95 \%$ CIs: $0.091-0.677$, Table 2 ). Cortisol results indicate gray wolves have higher levels of cortisol than black wolves ( $\beta=1.560,95 \%$ CIs: 0.208-2.911; Table 3, Fig. 3). However, the other best-fit model (Model no. 2 in Table 1 ) with $W_{i}=0.34$ did not include coat color so this effect should be interpreted with caution.

\subsection{Sex differences in behavior toward intruding wolves of known sex}

During PI interactions with male intruders, pack females were less likely than pack males to chase a lone male $(\beta=-0.749,95 \%$ CIs;
-1.143 to -0.354 ; Fig. 4). When female loners were chased by pack wolves, there was no difference in the participation rates between pack males and pack females ( $\beta=-0.458,95 \%$ CIs: -1.684 to 0.768 ; Table 4) perhaps due to the relative rarity of a pack encountering a lone female as intruders were often male $(75 \%, z=-10.3, p<0.001)$.

\section{Discussion}

Our analysis demonstrates that males are more likely to participate in aggressive behaviors than females. These results lend quantitative support to the hypothesis that males play a significant role in resource- and territory-protection (Stahler et al., 2013) and explains why packs with more males have higher success during intergroup interactions (Cassidy et al., 2015). In addition, aggression in males increases with age and gray wolves are more aggressive than black wolves, possibly due to differences in cortisol 
Table 4

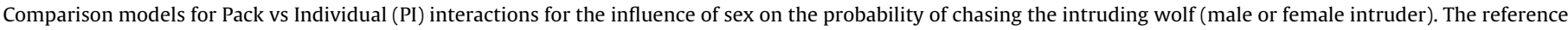
value for sex was male, for color was black, and for breeding status was non-breeder.

\begin{tabular}{|c|c|c|c|c|c|c|c|}
\hline & Pack wolf variables & $\beta$ & SE & $z$ & $P$ & $95 \%$ confidence interval for $\beta$ & \\
\hline \multirow[t]{7}{*}{ male intruder } & a. $\operatorname{RPS}^{*}$ & 0.066 & 0.013 & 5.00 & 0.000 & 0.040 & 0.092 \\
\hline & b. age & 0.229 & 0.062 & 3.69 & 0.000 & 0.107 & 0.351 \\
\hline & c. sex & -0.749 & 0.201 & -3.72 & 0.000 & -1.143 & -0.354 \\
\hline & d. color & 0.345 & 0.189 & 1.82 & 0.068 & -0.026 & 0.717 \\
\hline & e. breeding status & 0.039 & 0.257 & 0.15 & 0.880 & -0.464 & 0.542 \\
\hline & f. weight & -0.008 & 0.014 & -0.53 & 0.598 & -0.036 & 0.021 \\
\hline & cons & -1.323 & 0.723 & -1.83 & 0.067 & -2.740 & 0.094 \\
\hline \multirow[t]{7}{*}{ female intruder } & a. $\mathrm{RPS}^{*}$ & 0.198 & 0.050 & 4.00 & 0.000 & 0.101 & 0.295 \\
\hline & b. age & 0.274 & 0.168 & 1.63 & 0.102 & -0.055 & 0.602 \\
\hline & c. sex & -0.458 & 0.625 & -0.73 & 0.464 & -1.684 & 0.768 \\
\hline & d. color & 0.065 & 0.531 & 0.12 & 0.903 & -0.976 & 1.106 \\
\hline & e. breeding status & -0.130 & 0.660 & -0.20 & 0.844 & -1.424 & 1.164 \\
\hline & f. weight & -0.075 & 0.052 & -1.46 & 0.143 & -0.176 & 0.026 \\
\hline & cons & 2.500 & 2.597 & 0.96 & 0.336 & -2.591 & 7.590 \\
\hline
\end{tabular}

*Relative Pack Size.

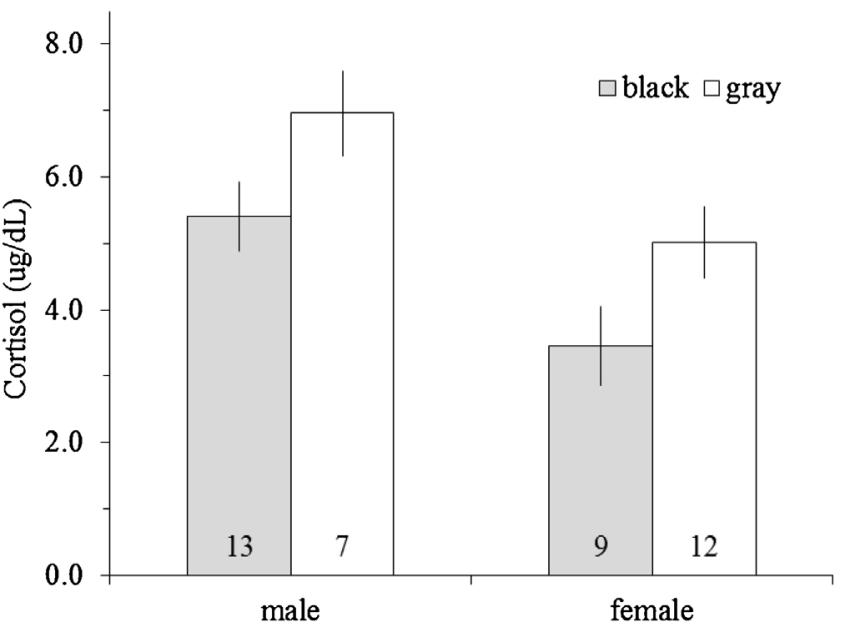

Fig. 3. Cortisol levels, for males vs females and black vs gray wolves $(n=41)$ with lines indicating SE.

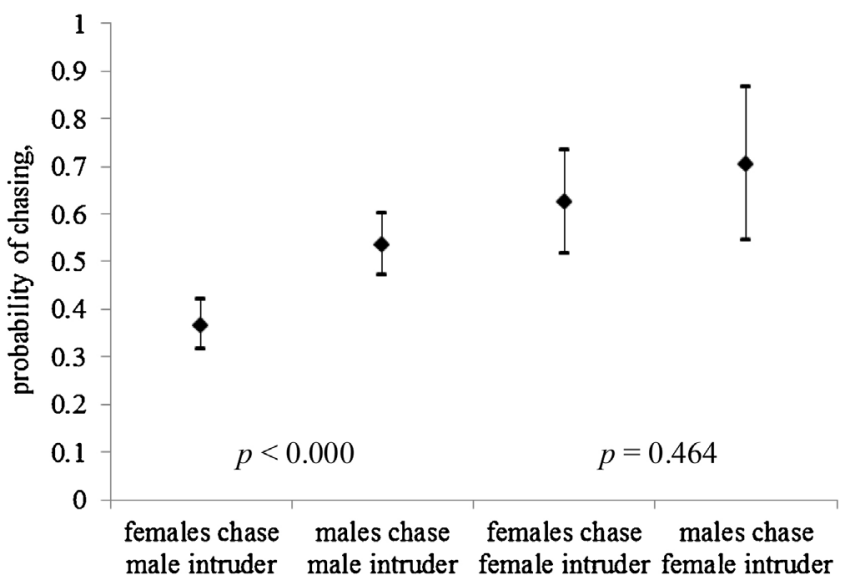

Fig. 4. Probability of male and female pack members chasing a single male or female intruder (with 95\% confidence intervals) from the best-fit model of PI interactions.

levels. These findings improve our understanding of trait-specific roles related to aggression and mating systems in group-living species. In addition to confirming individual-variation in aggressive behavior, our analysis confirms that wolves mediate their behavior based on a numerical assessment of their rival and are more likely to participate in a chase the more their own pack outnumbers the opponent. These results are similar to numerical assessment stud- ies in chimpanzees (Wilson et al., 2001) African lions (Mosser and Packer, 2009), and spotted hyenas (Benson-Amram et al., 2011).

\subsection{Sex and age effects on aggressive behavior}

Male-biased aggression often correlates with a polygynous mating system in which males maximize their reproductive output by fighting other males to maintain access to females (Lindenfors et al., 2007; Clutton-Brock, 2016). Although typically classified as monogamous breeders, gray wolves have been documented to exhibit cooperative breeding and flexible mating systems including various forms of polygamy and promiscuity (Harrington et al., 1982; Mech and Nelson, 1989; Mech and Boitani, 2003; Kleiman, 2011; Stahler et al., 2013) which may influence sexual dimorphism as males are 20\% larger than females (MacNulty et al., 2009a). Having a large body size has proven beneficial for wolves in hunting efficiency (MacNulty et al., 2009b). In addition, the correlation between sexual dimorphism and aggression suggests that males specialize in fighting conspecifics (Morris and Brandt, 2014).

When male and female behaviors differ during intergroup aggressive interactions, researchers have suggested it is because the two sexes have different motivations (Wrangham, 1980; Cheney, 1981; Kumar and Kurup, 1985; Watts, 1989; Kinnaird, 1992; Sicotte, 1993; Fashing, 2001). Several studies on primate species have concluded that males practice resource and mate defense while females are more likely to only practice resource defense (e.g. Cheney, 1981; Cheney and Seyfarth, 1987; Isbell, 1991; Kinnaird, 1992). In African lions, and even matriarchal spotted hyenas, males are especially aggressive toward other males, indicating they practice mate defense, whereas females practice offspring and resource defense (Packer et al., 1990; Grinnell et al., 1995; Heinsohn and Packer, 1995; Wolff and Peterson, 1998; Boydston et al., 2001).

If wolves practiced only resource defense against other packs, we might expect all of them (regardless of age, sex, breeding status, etc.) to be equally aggressive toward rival groups and intruding individuals. Further, the level of aggression for all pack members would be most affected by population or ecosystem changes such as a drop in prey numbers or an increase in wolf density creating increased competition for finite resources. Two related explanations for aggression include offspring-defense (kin selection) and maintaining pack numbers and competitiveness (Cassidy et al., 2015). Infanticide by neighboring packs has been recorded (Latham and Boutin, 2012; Smith et al., 2015) and would promote defense of offspring and, in turn, increases in pack size. However, the benefits and costs of participating are likely not uniform for each wolf, resulting in individuals with different participation patterns during conflicts. 
Male wolves direct aggression toward other groups and toward single male intruders. This likely works to protect current offspring investment and future reproductive opportunity as male wolves invest heavily in offspring through direct (e.g. feeding, cleaning, keeping warm) and indirect (e.g. fighting other packs for territory and resources) behaviors (Kleiman and Malcolm, 1981; Smith et al., 2015). More information may help elucidate the costs and benefits of female behavior during aggressive interactions. Mate acquisition may also be an ultimate benefit to aggression as males have sometimes assumed breeding positions in a rival pack left vacant after an aggressive interaction, and several new packs have formed after their packs interacted aggressively (Yellowstone Wolf Project unpublished data).

Age also has significant effects on critical events in wolf life history. Two- to three-year old wolves have the highest probability of success during hunts (MacNulty et al., 2009a), and female wolves around four to six years old produced the largest litters (Stahler et al., 2013). Both measures exhibited nonlinear trends peaking at apparent, optimal-age ranges for performance-related success; however, aggression towards intruders and other packs did not decrease at any age, and for males, actually increased. Older males may participate in aggressive interactions beyond their prime years due to more intense protection of mates, current offspring, and future breeding opportunity. These results suggest male wolf aggression fits the terminal investment hypothesis (Williams, 1966) which postulates that species showing age-related decline in reproductive value increase reproductive effort with age. In this case, the males become increasingly aggressive in defense of breeding opportunities as those opportunities become fewer with age.

Differences in behavior during aggressive inter-group encounters may suggest wolf packs experience a collective action problem where some individuals take advantage of group cooperation rewards without participating in the potentially costly behaviors (Olson, 1965; MacNulty et al., 2012). However, participation rates for all pack members were fairly high, indicating that wolves may instead practice group augmentation (Kingma et al., 2014) where pack members aid each other (Cassidy and McIntyre, 2016) and as a result maintain large pack sizes where they can all benefit from living in a large group. Based on this analysis, we believe group augmentation fits gray wolf behavior and there was little evidence of defection during encounters.

Familiarity might explain why male pack members exhibit less aggression than expected toward lone males. During some interactions between packs and lone males, the intruder interacted with the pack several times over a few days to a few months. Such behavior might foster familiarity while decreasing aggressive reactions from the pack wolves. It was not uncommon for lone males to breed with pack females or occasionally join the pack as a subordinate. A female wolf has only once been recorded joining an unrelated, established pack as a subordinate (Mech et al., 1998). With no chance of joining the pack, females likely do not initiate interactions and therefore most pack encounters with female intruders are accidental and rare.

\subsection{Breeding status effects on aggressive behavior}

Despite our predictions that breeding status would influence aggressive behavior (with breeders being more likely to show aggression) it was not an important factor ( $\beta$ : -0.169 , 95\% CIs: -0.508 to 0.170 ) in the best fit model. This may be due to the categorization of breeders in our dataset. We recorded if a wolf bred or not each year and used this as their breeding status category until the next breeding season. This method combined the dominant breeders, other wolves that bred within the pack but as subordinates and wolves that bred outside the pack into one group: breeders. These different types of breeders may exhibit different behaviors during encounters with other packs which could have resulted in the breeder category showing no apparent effect on aggression.

\subsection{Coat color effects on aggressive behavior}

Color was also included in our best model and gray-colored wolves had higher cortisol levels than black wolves. However, the second best-performing model did not include coat color and based on its $\mathrm{W}_{\mathrm{i}}$ of 0.34 could also be considered an appropriate descriptor of the data. It is possible that the K-locus, like other melanin-based coloration genes, is associated with physiological and behavioral traits (e.g. immune function, stress response) through pleiotropic effects on the melanocortin system (Ducrest et al., 2008) as has been shown in black dogs having lower basal cortisol levels (Bennett and Hayssen, 2010) and aggression rates (Houpt and Willis, 2001; Amat et al., 2009) than nonblack dogs. Our results indicate the K-locus may influence hormones and consequently influence behavior, as black wolves were less aggressive than gray wolves during aggressive encounters. Anderson et al. (2009) determined that the black coat color emerged in gray wolves when they interbred with domestic dogs (where the gene mutation originated), so perhaps hormonal or physiological factors related to domestication also play a role in differential behavior. Future work aims to evaluate these hypotheses.

\subsection{Conclusions}

This study demonstrates that male and female wolves behave differently during aggressive interactions with opponents. Males-the larger sex-consistently exhibit more intense aggression than females, likely to protect mates and offspring against single rivals and other groups. Further, males and females show differences in age-related effects on aggression throughout their lives with male aggressive behavior increasing quickly until 1.5 years (just before sexual maturity) then more slowly with age and female aggressive behavior levels remaining constant. Color also influenced aggressive behavior with gray wolves being more aggressive than black wolves as evidenced by hormonal differences.

Territorial groups that defeat their opponents likely experience higher survival and long-term stability by reducing their intraspecific mortality and by increasing their access to resources such as food and protected areas to raise young. These social groups are made up of individuals for whom the costs and benefits of engaging in an aggressive intergroup conflict vary. In wolves, certain individuals (gray-colored wolves and older males) are more aggressive than others and this can affect a group's competitive ability. Wolf packs with more adult males and old adults-the most aggressive individuals in the pack-have better chances of defeating an opponent (Cassidy et al., 2015), and those individuals are more valuable than females and younger wolves during interactions with other packs. These trait-specific differences in resource and territory defense indicate there is a "division of labor" in wolf packs (Mech, 1999) and suggests aggression is an adaptive response to competitive environments with certain individuals of great importance to the long-term success of the pack.

\section{Acknowledgments}

We thank Erin Stahler, Matt Metz, Rick McIntyre and numerous field technicians for their advice, guidance, and tireless work in data collection and logistics. This work would not be possible without the safe piloting of Roger Stradley from Gallatin Flying Service, Bob Hawkins from Hawkins and Powers, Inc. and Sky Aviation, Inc, and Mark Duffy from Central Copters, Inc. Mike Wilson and Glenn DelGiudice provided valuable insight on early drafts of this manuscript. We also thank the Cornell University Animal Health Diagnostic Lab 
and significant donors to the Yellowstone Wolf Project: Valerie Gates, Annie and Bob Graham, and Frank and Kay Yeager, as well as the U. S. National Park Service, and the U. S. Geological Survey, and National Science Foundation (DEB-0613730, DEB-1245373 and DEB-1021397). Any mention of trade, firm, or product names is for descriptive purposes only and does not imply endorsement by the U.S. government.

\section{Appendix A. Supplementary data}

Supplementary data associated with this article can be found, in the online version, at http://dx.doi.org/10.1016/j.beproc.2017. 01.011 .

\section{References}

Almasi, B., Jenni, L., Jenni-Eiermann, S., Roulin, A., 2010. Regulation of stress response is heritable and functionally linked to melanin-based coloration. J. Evol. Biol. 23, 987-996.

Altmann, J., 1974. Observational study of behavior: sampling methods. Behaviour 49, 227-266

Amat, M., Manteca, X., Mariotti, V.M., de la Torre, J.L.R., Fatjo, J., 2009. Aggressive behavior in the English cocker spaniel. J. Vet. Behav. 4, 111-117.

Anderson, T.M., vonHoldt, B.M., Candille, S.I., Musiani, M., Greco, C., Stahler, D.R., Smith, D.W., Padhukasahasram, B., Randi, E., Leonard, J.A., Bustamante, C.D., Ostrander, E.A., Tang, H., Wayne, R.K., Barsh, G.S., 2009. Molecular and evolutionary history of melanism in North American gray wolves. Science 323, 1339-1343.

Ballard, W.B., Matson, G.M., Krausman, P.R., 1995. Ecology and conservation of wolves in a changing world. In: N. Carbyn, L., Fritts, S.H., Seip, D.R. (Eds.). Canadian Circumpolar Institute, Occasional Publication 35, pp. 455-460.

Bangs, E.E., Fritts, S.H., 1996. Reintroducing the gray wolf to central Idaho and Yellowstone National Park. Wildl. Soc. Bull. 24, 402-413.

Bennett, A., Hayssen, V., 2010. Measuring cortisol in hair and saliva from dogs: coat color and pigment differences. Domest. Anim. Endocrinol. 39, 171-180.

Benson-Amram, S., Heinen, V.K., Dryer, S.L., Holekamp, K.E., 2011. Numerical assessment and individual call discrimination by wild spotted hyaenas, Crocuta crocuta. Anim. Behav. 82, 743-752.

Bonanni, R., Valsecchi, P., Natoli, E., 2010. Pattern of individual participation and cheating in conflicts between groups of free-ranging dogs. Anim. Behav. 79, 957-968.

Bonanni, R., Natoli, E., Cafazzo, S., Valsecchi, P., 2011. Free-ranging dogs assess the quantity of opponents in intergroup conflicts. Anim. Cogn. 14, 103-115.

Boydston, E.E., Morelli, T.L., Holekamp, K.E., 2001. Sex differences in territorial behavior exhibited by the spotted hyena (Crocuta crocuta). Ethology 107 , 369-385.

Burnham, K.P., Anderson, D.R., 1998. Model Selection and Inference: a Practical Information-theoretic Approach, first ed. Springer-Verlag, New York, New York, USA

Butler, M.J., Ballard, W.B., Whitlaw, H.A., 2006. Physical characteristics, hematology, and serum chemistry of free-ranging gray wolves (Canis lupus) in south-central Alaska. Can. Field Nat. 120, 202-205.

Candille, S.I., Kaelin, C.B., Cattanach, B.M., Yu, B., Thompson, D.A., Nix, M.A., Kerns, J.A., Schmutz, S.M., Millhauser, G.L., Barsh, G.S., 2007. A beta-defensin mutation causes black coat color in domestic dogs. Science 318, 1418-1423.

Cassidy, K.A., McIntyre, R.T., 2016. Do gray wolves (Canis lupus) support pack mates during aggressive inter-pack interactions? Anim. Cogn. 19, 1-9.

Cassidy, K.A., MacNulty, D.R., Stahler, D.R., Smith, D.W., Mech, L.D., 2015. Group composition effects on aggressive inter-pack interactions of gray wolves in Yellowstone National Park. Behav. Ecol. 26, 1352-1360.

Cheney, D.L., Seyfarth, R.M., 1987. The influence of intergroup competition on the survival and reproduction of female vervet monkeys. Behav. Ecol. Sociobiol. 21 375-386.

Cheney, D., 1981. Intergroup encounters among free-ranging vervet monkeys. Folia Primatol. (Basel) 35, 124-146.

Clutton-Brock, T.H., 2016. Mammal Societies. Wiley, West Sussex, United Kingdom.

Creel, S., Creel, N.M., 1998. Six ecological factors that may limit African wild dogs, Lycaon pictus. Anim. Conserv. 1, 1-9.

Creel, S., 2005. Dominance, aggression, and glucocorticoid levels in social carnivores. J. Mammal. 86, 255-264.

Cubaynes, S., MacNulty, D.R., Stahler, D.R., Quimby, K.A., Smith, D.W., Coulson, T., 2014. Density-dependent intraspecific aggression regulates survival in northern Yellowstone wolves (Canis lupus). J. Anim. Ecol. 83, 1344-1356.

Darwin, C., 1871. The Descent of Man and Selection in Relation to Sex. John Murray, London, UK.

Dirks, R.A., Martner, B.E., 1982. The Climate of Yellowstone and Grand Teton National Parks. Natural Resources Report, National Park Service, United States Department of the Interior, Washington D.C., USA

Doolan, S., Macdonald, D., 1996. Dispersal and extra-territorial prospecting by slender-tailed meerkats (Suricata suricatta) in the south-western Kalahari. J. Zool. 240, 59-73.
Ducrest, A.L., Keller, L., Roulin, A., 2008. Pleiotropy in the melanocortin system, coloration and behavioural syndromes. Trends Ecol. Evol. 23, 502-510.

Eubanks, R.L.v, 1984. Approximate regression models and spines. Commun. Stat. Theory Math. 13, 433-484

Fashing, P.J., 2001. Activity and ranging patterns of guerezas in the Kakamega forest: intergroup variation and implications for intragroup feeding competition. Int. J. Primatol. 22, 549-577.

Feldman, H.N., 1990. Sociality and Cooperative Maternal Care in Domestic Cats. PhD Thesis. University of Cambridge.

Furrer, R.D., Kyabulima, S., Willems, E.P., Cant, M.A., Manser, M.B., 2011. Location and group size influence decisions in simulated intergroup encounters in banded mongooses. Behav. Ecol. 22, 493-500.

Gipson, P.S., Ballard, W.B., Nowak, R.M., Mech, L.D., 2000. Accuracy and precision of estimating age of gray wolves by tooth wear. J. Wildl. Manage. 64, 752-758.

Grinnell, J., Packer, C., Pusey, A.E., 1995. Cooperation in male lions: kinship, reciprocity or mutualism? Anim. Behav. 49, 95-105.

Harrington, F.H., Paquet, P.C., Ryon, J., Fentress, J.C., 1982. Monogamy in wolves: a review of the evidence. In: Harrington, F., Paquet, P. (Eds.), Wolves of the World: Perspectives of Behavior, Ecology and Conservation. Noyes Publications, Park Ridge, New Jersey, pp. 209-222.

Heinsohn, R., Packer, C., 1995. Complex cooperative strategies in group-territorial African lions. Science 269, 1260-1262.

Heinsohn, R., 1997. Group territoriality in two populations of African lions. Anim. Behav. 53, 1143-1147.

Henschel, J.R., Skinner, J.D., 1991. Territorial behaviour by a clan of spotted hyaenas (Crocuta crocuta). Ethology 88, 223-235.

Houpt, K.A., Willis, M., 2001. Genetics of behaviour. In: Ruvinsky, A., Sampson, J. (Eds.), The Genetics of the Dog. CABI Publishing, Wallingford, pp. 371-400.

Houston, D., 1982. The Northern Yellowstone Elk: Ecology and Management. Macmillian Publishing Company, New York, NY.

Isbell, L.A., 1991. Contest and scramble competition: patterns of female aggression and ranging behavior among primates. Behav. Ecol. 2, 143-155.

Kingma, S.A., Santema, P., Taborsky, M., Komdeur, J., 2014. Group augmentation and the evolution of cooperation. Trends Ecol. Evol. 29, 476-484.

Kinnaird, M.F., 1992. Variable resource defense by the Tana river crested mangabey. Behav. Ecol. Sociobiol. 31, 115-122.

Kleiman, D.G., Malcolm, J.R., 1981. The evolution of male parental investment in mammals. In: Gubernick, D.J., Klopfer, P.H. (Eds.), Parental Care in Mammals. Plenum Publishing Corporation, New York, New York, pp. 347-388.

Kleiman, D.G., 2011. Canid mating systems, social behavior, parental care and ontogeny: are they flexible? Behav. Genet. 41, 803-809.

Koch, F., Signer, J., Kappeler, P.M., Fichtel, C., 2016. Intergroup encounters in Verreaux's sifakas (Propithecus verreauxi): who fights and why? Behav. Ecol. Sociobiol. 70, 797-808.

Kruk, M.R., Halász, J., Meelis, W., Haller, J., 2004. Fast positive feedback between the adrenocortical stress response and a brain mechanism involved in aggressive behavior. Behav. Neurosci. 118, 1062-1070.

Kumar, A., Kurup, G.U., 1985. Inter-troop interactions in the lion-tailed macaque, Macaca silenus. In: Heltne, P.G. (Ed.), The Lion-tailed Macaque: Status and Conservation. Wiley-Liss, New York, New York, pp. 91-107.

Landon, D.B., Waite, C.A., Peterson, R.O., Mech, L.D., 1998. Evaluation of age determination techniques for gray wolves. J. Wildl. Manage. 62, 674-682.

Latham, A.D.M., Boutin, S., 2012. Wolf, Canis lupus, pup mortality: interspecific predation or non-parental infanticide? Can. Field Nat. 125, 158-161.

Lindenfors, P., Gittleman, J.L., Jones, K.E., 2007. Sexual size dimorphism in mammals. In: Fairburn, D.J., Blanckenhorn, W.U., Szekely, T. (Eds.), Sex, Size and Gender Roles: Evolutionary Studies of Sexual Size Dimorphism. Oxford University Press Oxford, United Kingdom, pp. 16-26.

MacCormick, H.A., MacNulty, D.R., Bosacker, A.L., Lehman, C., Bailey, A., Collins, D.A., Packer, C., 2012. Male and female aggression: lessons from sex, rank, age, and injury in olive baboons. Behav. Ecol. 23, 684-691.

MacNulty, D.R., Smith, D.W., Mech, L.D., Eberly, L.E., 2009a. Body size and predatory performance in wolves: is bigger better? J. Anim. Ecol. 78, 532-539.

MacNulty, D.R., Smith, D.W., Vucetich, J.A., Mech, L.D., Stahler, D.R., Packer, C., 2009b. Predatory senescence in ageing wolves. Ecol. Lett. 12, 1347-1356.

MacNulty, D.R., Smith, D.W., Mech, L.D., Vucetich, J.A., Packer, C., 2012. Nonlinear effects of group size on the success of wolves hunting elk. Behav. Ecol. 23, 75-82.

Majolo, B., Ventura, R., Koyama, N.F., 2005. Sex, rank and age differences in the Japanese macaque (Macaca fuscata yakui) participation in intergroup encounters. Ethology 111, 455-468.

McComb, K., Packer, C., Pusey, A., 1994. Roaring and numerical assessment in contests between groups of female lions, Panthera leo. Anim. Behav. 47 379-387.

Mech, L.D., Boitani, L., 2003. Wolves: Behavior, Ecology, and Conservation. University of Chicago Press, Chicago, Illinois.

Mech, L.D., Nelson, M.E., 1989. Polygyny in a wild wolf pack. J. Mammal. 70, 675-676.

Mech, L.D., Adams, L.G., Meier, T.J., Burch, J.W., Dale, B.W., 1998. The Wolves of Denali. University of Minnesota Press, Minneapolis, Minnesota.

Mech, L.D., 1977. Productivity, mortality, and population trends of wolves in northeastern Minnesota. J. Mammal. 58, 559-574.

Mech, L.D., 1994. Buffer zones of territories of gray wolves as regions of intraspecific strife. J. Mammal. 75, 199-202.

Mech, L.D., 1999. Alpha status, dominance, and division of labor in wolf packs. Can. J. Zool. 77, 1196-1203. 
Mech, L.D., 2006. Age-related body mass and reproductive measurements of gray wolves in Minnesota. J. Mammal. 87, 80-84.

Metz, M.C., Smith, D.W., Vucetich, J.A., Stahler, D.R., Peterson, R.O., 2011. Seasonal patterns of predation for gray wolves in the multi-prey system of Yellowstone National Park. J. Anim. Ecol. 81, 553-563.

Milinski, M., Parker, G.A., 1991. Competition for resources. In: Krebs, J.R., Davies, N.B. (Eds.), Behavioural Ecology: an Evolutionary Approach. Blackwell, Oxford, pp. 137-168.

Miller, R., 1981. Male aggression, dominance and breeding behavior in Red Desert feral horses. Zeitschrift für Tierpsychologie 57, 340-351.

Mills, M.G.L., 1983. Behavioural mechanisms in territory and group maintenance of the brown hyaena (Hyaena brunnea) in the southern Kalahari. Anim. Behav. 31, 503-510.

Morris, J.S., Brandt, E.K., 2014. Specialization for aggression in sexually dimorphic skeletal morphology in gray wolves (Canis lupus). J. Anat. 225, 1-11.

Mosser, A., Packer, C., 2009. Group territoriality and the benefits of sociality in the African lion, Panthera leo. Anim. Behav. 78, 359-370.

Muller, M.N., Wrangham, R.W., 2004. Dominance, aggression and testosterone in wild chimpanzees: a test of the 'challenge hypothesis'. Anim. Behav. 1, $113-123$.

Murray, D.L., Smith, D.W., Bangs, E.E., Mack, C., Oakleaf, J.K., Fontaine, J., Boyd, D., Jimenez, M., Niemeyer, C., Meier, T.J., Stahler, D.R., Holyan, J., Asher, V.J., 2010. Death from anthropogenic causes is partially compensatory in recovering wolf populations. Biol. Conserv. 143, 2514-2524.

Olson, M., 1965. The Logic of Collective Action: Public Goods and the Theory of Groups. Harvard University Press, Cambridge, Massachusetts.

Packer, C., Scheel, D., Pusey, A.E., 1990. Why lions form groups: food is not enough. Am. Nat. 136, 1-19.

Pal, S.K., Ghosh, B., Roy, S., 1998. Agonistic behaviour of free-ranging dogs (Canis familiaris) in relation to season, sex and age. Appl. Anim. Behav. Sci. 59, 331-348.

Peters, R.P., Mech, L.D., 1975. Scent-marking in wolves: radio-tracking of wolf packs has provided definite evidence that olfactory sign is used for territory maintenance and may serve for other forms of communication within the pack as well. Am. Sci. 63, 628-637.

Pusey, A.E., Packer, C., 1997. The ecology of relationships. In: Krebs, J.R., Davies, N.B. (Eds.), Behavioural Ecology: an Evolutionary Approach. , 4th ed. Blackwell, Oxford, pp. 254-283.

Reimers, T.J., Salerno, V.J., Lamb, S.V., 1996. Validation and application of solid-phase chemiluminescent immunoassays for diagnosis of endocrine diseases in animals. Comp. Haematol. Int. J. 6, 170-197.

Rood, J.P., 1983. The social system of the dwarf mongoose. Spec. Publ. Am. Soc. Mammal. 7, 454-488.

Rosado, B., Garcia-Belenguer, S., Leon, M., Chacon, G., Villegas, A., Palacio, J., 2010. Blood concentrations of serotonin, cortisol and dehydroepiandrosterone in aggressive dogs. Appl. Ani. Behav. Sci. 123, 124-130.

Seber, G.A.F., Wild, C.J., 2003. Nonlinear Regression. John Wiley and Sons, New York, New York, USA.

Sicotte, P.E., 1993. Inter-group encounter and female transfer in mountain gorilla: influence of group composition on male behavior. Am. J. Primatol. 30, 21-36.

Sikes, R.S., Gannon, W.L., 2011. Guidelines of the American Society of Mammalogists for the use of wild mammals in research. J. Mammal. 92 235-253.

Singh, A.K., Jiang, Y., White, T., Spassova, D., 1997. Validation of a nonradioactive chemiluminescent immunoassay methods for the analysis of thyroxine and cortisol in blood samples obtained from dogs, cats, and horses. J. Vet. Diagn. Invest. 9, 261-268.
Smith, D.W., Bangs, E.E., 2009. Reintroduction of wolves to Yellowstone National Park: history, values, and ecosystem restoration. In: Hayward, M.W., Somers, M. (Eds.), Reintroduction of Top-order Predators. Wiley-Blackwell, Oxford, UK, pp. 92-125.

Smith, D.W., Drummer, T.D., Murphy, K.M., Guernsey, D.S., Evans, S.B., 2004. Winter prey selection and estimation of wolf kill rates in Yellowstone National Park, 1995-2000. J. Wildl. Manage. 68, 153-166.

Smith, D.W., Stahler, D.R., Albers, E., McIntyre, R., Metz, M., Irving, J., Raymond, R., Anton, C., Cassidy, K., Bowersock, N., 2011. Yellowstone Wolf Project, Annual Report, 2010. Yellowstone National Park, Mammoth Hot Springs, Wyoming : Yellowstone Center for Resources.

Smith, D.W., Metz, M., Cassidy, K.A., Stahler, E.E., McIntyre, R.T., Almberg, E.S., Stahler, D.R., 2015. Infanticide in wolves: seasonality of mortalities and attacks at dens support evolution of territoriality. J. Mammal. 96, 1174-1183.

Stahler, D.R., MacNulty, D.R., Wayne, R.K., vonHoldt, B., Smith, D.W., 2013. The adaptive value of morphological, behavioral, and life history traits in reproductive female wolves. J. Anim. Ecol. 82, 222-234.

Summers, C.H., Winberg, S., 2006. Interactions between the neural regulation of stress and aggression. J. Exp. Biol. 209, 4581-4589.

Watts, D.P., 1989. Infanticide in mountain gorillas: new cases and a reconsideration of the evidence. Ethology 81, 1-18.

Willems, E.P., van Schaik, C.P., 2015. Collective action and the intensity of between-group competition in nonhuman primates. Behav. Ecol. 26, 625-631.

Willems, E.P., Hellriegel, B., van Schaik, C.P., 2013. The collective action problem in primate territory economics. Proc. R. Soc. B: Biol. Sci. 280, 1-7.

Williams, G.C., 1966. Adaptation and Natural Selection. Princeton University Press, Princeton, NJ.

Wilson, M.L., Wrangham, R.W., 2003. Intergroup relations in chimpanzees. Annu. Rev. Anthropol. 32, 363-392.

Wilson, M.L., Hauser, M.D., Wrangham, R.W., 2001. Does participation in intergroup conflict depend on numerical assessment, range location, or rank for wild chimpanzees? Anim. Behav. 61, 1203-1216.

Wilson, M.L., Kahlenberg, S.M., Wells, M., Wrangham, R.W., 2012. Ecological and social factors affect the occurrence and outcomes of intergroup encounters in chimpanzees. Anim. Behav. 83, 277-291.

Wilson, M.L., Boesch, C., Fruth, B., Furuichi, T., Gilby, I.C., Hashimoto, C., Hobaiter C.L., Hohmann, G., Itoh, N., Koops, K., Lloyd, J.N., Matsuzawa, T., Mitani, J.C., Mjungu, D.C., Morgan, D., Muller, M.N., Mundry, R., Nakamura, M., Pruetz, J., Pusey, A.E., Riedel, J., Sanz, C., Schel, A.M., Simmons, N., Waller, M., Watts, D.P., White, F., Wittig, R.M., Zuberbühler, K., Wrangham, R.W., 2014. Lethal aggression in Pan is better explained by adaptive strategies than human impacts. Nature 513, 414-417.

Wolff, J.O., Peterson, J.A., 1998. An offspring-defense hypothesis for territoriality in female mammals. Ethol. Ecol. Evolut. 10, 227-239.

Wrangham, R.W., 1980. An ecological model of female-bonded primate groups. Behaviour 75, 262-300.

York, C.A., Schulte, B.A., 2014. The relationship of dominance, reproductive state and stress in female horses (Equus caballus). Behav. Process. 107, 15-21.

vonHoldt, B.M., Stahler, D.R., Smith, D.W., Earl, D.A., Pollinger, J.P., Wayne, R.K., 2008. The genealogy and genetic viability of reintroduced Yellowstone grey wolves. Mol. Ecol. 17, 252-274. 